IInstituto Agronômico de Pernambuco (IPA), Av. Gal San Martin, 1371, Bongi, CEP 50761-000, Recife, PE, Brasil 2Bolsista de Pós-doutorado PNPD/ CAPES/FINEP

${ }^{3}$ Bolsista de apoio técnico CNPq

* autor correspondente

凶maria.luiza@ipa.br

\section{Diversidade e potencial de solubilização de fosfato in vitro por bactérias endofíticas associadas à cultura da palma forrageira (Opuntia e Nopalea) em Pernambuco}

\author{
Diversity and potential of solubilization of phosphate in vitro \\ by endophytic bacteria associated with the cultivation of \\ forage Palm (Opuntia and Nopalea) in Pernambuco state, \\ Brazil
}

Maria Luiza Ribeiro Bastos da Silva ${ }^{1,2 *}$, Carolina dos Santos Figueroa ${ }^{1,3}$, Adália Cavalcanti do Espírito Santo Mergulhão ${ }^{1}$, Maria do Carmo Catanho Pereira de Lyra' ${ }^{1}$
RESUMO: Bactérias diazotróficas endofíticas possuem mecanismos que, associadas à cultura da palma, podem contribuir para o crescimento e o desenvolvimento desta planta no Nordeste do Brasil, já que a mesma tem grande importância econômica, por ser o alimento principal dos animais na região semiárida. $\mathrm{O}$ objetivo deste estudo foi caracterizar estas bactérias endofíticas da palma quanto à capacidade de solubilizar fosfato inorgânico, além de comparar a diversidade dessas bactérias presentes nas regiões do semiárido pernambucano. Foi confirmada a presença de bactérias diazotróficas solubilizadoras de fosfato inorgânico associado às palmas cultivadas, oriundas dos BAGs (banco ativo de germopalsma) de Caruaru e Arcoverde. Usando-se o índice de diversidade, como o de Shannon-Weaver, observou-se que houve diversidade de bactérias diazotróficas endofíticas. Para a análise do índice de Equitabilidade de Pielou, observou-se que não houve dominância das bactérias nas regiões estudadas.

PALAVRAS-CHAVE: Comunidade endofítica, índice de diversidade, bactérias diazotróficas.
ABSTRACT: Diazotrophic bacteria present mechanisms that, when associated with the culture offorage Palm, can contribute to the growth and development of this plant in northeastern Brazil. Forage Palm is of great economic importance because it is the main animal feed in the semiarid region. The aim of this study was to characterize these endophytic bacteria in Palm plants regarding their ability to solubilize inorganic phosphate and compare their diversity in semiarid regions of Pernambuco state. We confirmed the presence of diazotrophs solubilizing inorganic phosphate associated with the coming of cultivated palm from the AGBs (Active Germplasm Bank) of Caruaru and Arcoverde. Diversity of diazotrophic bacteria was observed using the Shannon-Weaver diversity index. Analysis of the Pielou's equitability index showed no dominance of bacteria in the regions studied.

KEYWORDS: Endophytic community, diversity index, diazotrophic bacteria.
A cultura da palma forrageira na Região Nordeste do Brasil tem uma grande importância econômica, por ser o alimento principal dos animais na região semiárida. No Estado de Pernambuco, são cultivadas duas espécies de palma, a Opuntia ficus-indica Mill, com as cultivares gigante, redonda e clone IPA-20, e a Nopalea cochenillifera Salm Dyck, sendo que a cultivar mais plantada é a miúda ou doce (SANTOS et al., 
2006). A palma forrageira é uma cultura relativamente exigente quanto às características físico-químicas do solo. Dessa forma, para propiciar boas condições de desenvolvimento e produtividade, deve-se dar importância ao suprimento de fósforo. Tem-se, por hipótese, que as cactáceas estabelecem naturalmente associação com as bactérias diazotróficas endofíticas e podem se beneficiar da interação planta-bactéria na fase de crescimento inicial.

A habilidade das bactérias endofíticas em relação à solubilização do fosfato inorgânico vem despertando grande interesse (SOBRAL, 2003; SANTOS et al., 2012). É interessante ressaltar que as bactérias endofíticas com capacidade de solubilizar fosfato inorgânico ganham importância durante o processo de colonização, pois podem, inicialmente, colonizar superficialmente o hospedeiro e, consequentemente, provê-lo deste mineral essencial para o desenvolvimento vegetal (PEDRINHO, 2009).

As bactérias solubilizadoras de fósforo (BSF), quando utilizadas como biofertilizante, propiciam grandes vantagens para a planta, principalmente aumentando a produtividade (INUI-KISHI et al., 2012). Mesmo a diversidade de bactérias solubilizadoras de $\mathrm{P}$ presentes no solo sendo alta, os níveis populacionais observados geralmente são baixos, para que ocorra uma competição com outras bactérias comumente associadas à rizosfera. Para que a quantidade de $\mathrm{P}$ liberado por estes organismos seja suficiente para promover o crescimento vegetal e aumentar a resistência a doenças, deve-se promover a inoculação destes organismos em concentrações elevadas (BASHAN; HOLGUIN; DE-BASHAN, 2004; SALA et al., 2005).

Silva et al. (2011) mostraram, através de uma avaliação in vitro, que podem isolar bactérias solubilizadoras de fosfatos de forma segura e efetiva, e utilizar estes BSF como inoculantes para aumentar os mecanismos de sobrevivência destas bactérias nos solos. Considerando-se que existem poucas informações sobre BSF na cultura da palma forrageira (Opuntia e Nopalea), faz-se necessário intensificar os estudos que possam contribuir efetivamente para um melhor aproveitamento do $\mathrm{P}$ no solo por essas plantas. Os objetivos principais deste estudo foram selecionar bactérias endofíticas associadas à cultura da palma quanto à capacidade de solubilizar fosfato inorgânico e comparar a diversidade dessas bactérias presentes nas regiões do Agreste e do Sertão de Pernambuco.

Amostras de cladódios de palma foram obtidas nas regiões do Agreste e do Sertão de Pernambuco, do Instituto Agronômico de Pernambuco (IPA). Após a coleta, as amostras vegetais foram lavadas com sabão neutro em água corrente, colocadas em etanol a $70 \%$ por 5 minutos e cortadas no centro do cladódio para evitar, ao máximo, a contaminação com o meio externo. Bactérias endofíticas de cladódios de palma foram isoladas, segundo Döbereiner, Baldani e Baldani (1995). Para tanto, cerca de $10 \mathrm{~g}$ de tecido vegetal de cada amostra foram lavados com água corrente, triturados e misturados em $90 \mathrm{~mL}$ de solução salina $(\mathrm{NaCl}$ 0,5\%), e diluídos serialmente $\left(10^{1}-10^{7}\right)$. De cada diluição, foram retiradas alíquotas de $0,1 \mathrm{~mL}$, sendo estas inoculadas em frascos de vidro contendo os meios de cultura NFb, LG, LGI, LGI-P e JNFb. Estes foram incubados a $30{ }^{\circ} \mathrm{C}$ e o crescimento bacteriano foi avaliado aos
3, 5 e 7 dias, verificando-se o aparecimento ou não da película característica para as bactérias diazotróficas endofíticas.

Para a solubilização, os isolados foram crescidos em $5 \mathrm{~mL}$ do meio DYGS líquido (RODRIGUES NETO; MALAVOLTA JÚNIOR; VICTOR, 1986) durante 48 h, a $28^{\circ} \mathrm{C}$, sob agitação de $150 \mathrm{rpm}$. A capacidade de solubilização de fosfatos foi verificada segundo Verma, Ladha e Tripathi (2001), modificado (SANTOS et al., 2012), fosfato insolúvel (10 g/L de glicose; $5 \mathrm{~g} / \mathrm{L}$ de $\mathrm{NH}_{4} \mathrm{Cl} ; 1 \mathrm{~g} / \mathrm{L}$ de $\mathrm{NaCl} ; 1 \mathrm{~g} / \mathrm{L}$ de $\mathrm{MgSO}_{4} .7 \mathrm{H}_{2} \mathrm{O} ; 4 \mathrm{~g} / \mathrm{L}$ de $\mathrm{CaHPO}_{4} ; 15 \mathrm{~g} / \mathrm{L}$ de agar; $\mathrm{pH}$ 7,2). Em cada placa, foram colocados $5 \mu \mathrm{L}$ do crescimento bacteriano com três repetições em pontos equidistantes. As placas foram incubadas a $28^{\circ} \mathrm{C}$ por $72 \mathrm{~h}$ e, em seguida, foi verificada a presença de área solubilizada (capacidade de solubilizar). Para o cálculo do índice de solubilização (IS), foi utilizada a razão entre o diâmetro do halo de solubilização ( $\phi$ Halo) e o diâmetro da colônia bacteriana ( $\varphi$ Colônia) correspondente $(\mathrm{IS}=\varphi$ Halo $(\mathrm{mm}) / \varphi$ Colônia (mm)) (BERRAQUERO; BAYA; CORMENZANA, 1976; CHAGAS JUNIOR et al., 2010). A partir destes dados, foi obtida a relação entre os diâmetros do halo e da colônia, utilizado na avaliação do potencial de solubilização.

Foram calculados os Índices de Diversidade de ShannonWeaver (1949) e de Equitabilidade de Pielou (1959).

Observou-se a ocorrência de bactérias endofíticas nas amostras de cladódios de palma nas duas regiões estudadas. Foram isoladas 52 bactérias de cinco diferentes meios de enriquecimento: NFb, LG, LGI, LGI-P e JNFb. Foi detectada maior presença em quantidade de bactérias quando o isolamento ocorreu no meio NFb, em comparação aos demais. Apesar de os meios de cultura serem semiespecíficos para os gêneros Azospirillum (NFb e LGI), Azotobacter e Azomonas (LG), Gluconacetobacter (LGI-P) e Herbaspirillum (JNFb), não se pode afirmar que todos os isolados obtidos em cada meio pertençam a tais gêneros, uma vez que várias bactérias associativas e de vida livre podem ser isoladas a partir de meios semissólidos livres de N (KIRCHHOF et al., 1997). De acordo com Nóbrega et al. (2004), os meios semisseletivos favorecem o isolamento dos gêneros desejados, porém permitem o isolamento de representantes de outras espécies. Assim, é importante que esses isolados também sejam caracterizados pela análise do gene $16 \mathrm{~S}$ rRNA, que poderá indicar o gênero ou a espécie do isolado bacteriano. Os resultados encontrados se assemelham ao que foi observado no estudo de ocorrência de bactérias endofíticas do gênero Azospirillum em arroz, por Cardoso et al. (2010), os quais afirmam a necessidade dos isolados serem caracterizados quanto às suas características fenotípicas, fisiológicas e genéticas, para confirmação das espécies.

Observou-se que, das 52 bactérias diazotróficas endofíticas de cladódio de palma, 46 foram capazes de solubilizar fosfato inorgânico in vitro, apresentando a formação de halo claro ao redor das colônias (Figura 1). O entendimento da capacidade e da eficiência de microrganismos em solubilizar fosfatos pode levar à seleção de isolados com alto potencial de uso para a inoculação em plantas (SOUCHIE et al., 2005). As BSF aumentam a disponibilidade de fosfato viável para a planta, promovendo o desenvolvimento vegetal em condições de campo 


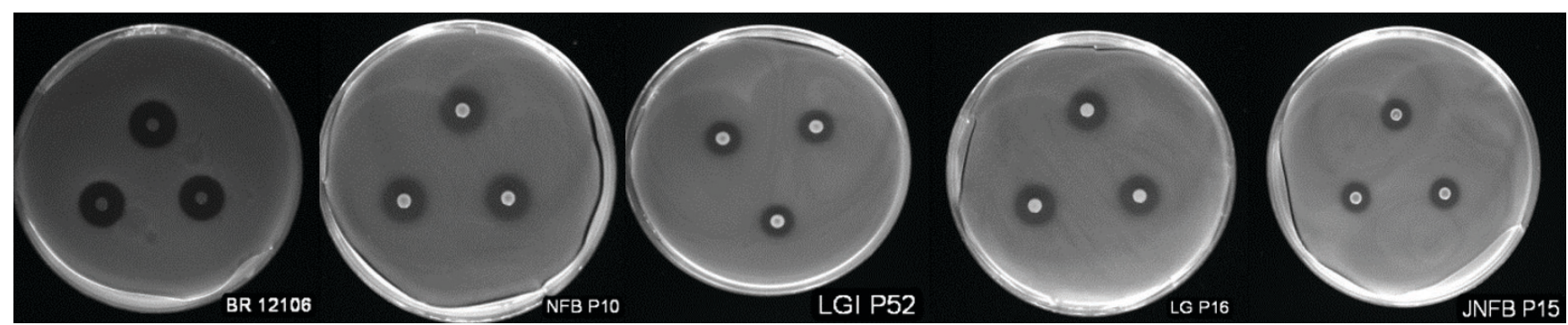

Figura 1. Capacidade de solubilização dos isolados selecionados no $15 .^{\circ}$ dia após a inoculação.

Tabela 1. Índice de solubilização (diâmetro do halo solubilizado/diâmetro da colônia) de isolados de palma.

\begin{tabular}{ccc}
\hline IS & Agreste & Sertão \\
\hline Não & 02 & 02 \\
Baixa & 07 & 05 \\
Média & 15 & 11 \\
Alta & 07 & 03 \\
\hline
\end{tabular}

IS = Índice de Solubilização (Não = não solubilizou; Baixa $=$ IS $<2$; Média $=2$ $<$ IS $<3$; Alta $=$ IS $>3$ ).

Tabela 2. Índices de diversidade e equitabilidade dos isolados de palma obtidos de duas regiões - Agreste e Sertão - de Pernambuco.

\begin{tabular}{cccc}
\hline Local / Índices & Total de isolados & H & E \\
\hline Agreste & 30 & 0,14 & 0,10 \\
Sertão & 22 & 0,16 & 0,10 \\
Total & 52 & & \\
\hline
\end{tabular}

$\mathrm{H}=$ Shannon-Weaver; $\mathrm{E}=$ Equitabilidade de Pielou.

(VERMA; LADHA; TRIPATHI, 2001; GYANESHWAR et al., 2002; COMPANT; CLÉMENT; SESSITSCH, 2010).

A maioria dos isolados apresentou IS médios $(2<$ IS $<3)$; entretanto, dez isolados e as duas bactérias utilizadas como padrões de solubilização (BR12106 e BR11284) apresentaram alto índice de solubilização (IS > 3) e o isolado JNFB P15 apresentou um resultado interessante, com IS $=4,0$. Este foi então considerado como um bom solubilizador, já que a capacidade para solubilizar fosfatos é feita por meio de diferentes mecanismos, especialmente pela produção de ácidos (WHITELAW, 2000; SILVA FILHO; NARLOCH; SCHARF, 2002). Os isolados - LG-P2, LG-P54, JNFb-P28 e NFB-P64 - foram considerados não solubilizadores, por não apresentarem a formação de halo no meio com fosfato após 18 dias de crescimento (Figura 1; Tabela 1).

Dados obtidos por Oliveira et al. (2009) indicaram que, para que uma bactéria seja considerada como boa solubilizadora de fosfato, o IS deve ser igual ou superior a 2,0. Esses índices de solubilização e a proporção com que estes foram encontrados são semelhantes aos obtidos por Silva Filho e Vidor (2000), Massenssini (2007) e Nautiyal (1999), em que se obteve o diâmetro dos halos variando de 2 a 7 mm. Silva et al. (2011), trabalhando com a ocorrência de BSF nas raízes de plantas de importância econômica em duas regiões do Amazonas, concluíram que as amostras tiveram diversidade e variaram com o local e as espécies vegetais estudadas. A capacidade de solubilização de fósforo em bactérias promotoras de crescimento em plantas permitiu uma melhor identificação dos isolados (INUI-KISHI et al., 2012).

Com os resultados obtidos pelos isolados, é interessante ressaltar que a interação bactéria-planta favorece a promoção do crescimento vegetal, em que o microrganismo consegue disponibilizar o nutriente para suas atividades e para a planta. Portanto, a capacidade das bactérias endofíticas em solubilizar fosfato inorgânico tem sido alvo de grande interesse por parte dos microbiologistas agrícolas, pois esta característica apresenta um grande potencial para a promoção de crescimento vegetal (SOBRAL, 2003).

Para conhecermos a diversidade das bactérias, foi usado o Índice de Shannon-Weaver, sendo verificado um discreto aumento na diversidade das bactérias endofíticas presentes na região do Sertão $(0,16)$ quando comparada com as do Agreste $(0,14)$ (Tabela 2). Tan, Hurek e Reinhold-Hurek (2003) relataram que fatores ambientais são determinantes da estrutura da comunidade de diazotróficos. Os resultados obtidos sugerem que diferenças regionais podem influenciar a comunidade bacteriana e que, para obtenção de melhor exploração do potencial das bactérias diazotróficas solubilizadoras de fosfato, tais diferenças podem ser uma perspectiva para melhorar o uso destas bactérias como promotoras de crescimento nas plantas estudadas.

Com relação ao índice de Equitabilidade (E), observou-se que não houve alteração para as regiões do Agreste e do Sertão de Pernambuco, cujo valor médio calculado foi de 0,10 (Tabela 2). Esses resultados sugerem que a distribuição das bactérias diazotróficas endofíticas analisadas foi uniforme entre regiões do Agreste e do Sertão para este estudo. Santos (2001) relata que quanto menor a dominância, maior a equitabilidade de espécies de uma comunidade, mais estável a mesma e maior resistência aos impactos ambientais que possa vir a sofrer.

Portanto, é imprescindível que esses isolados sejam caracterizados geneticamente para fins de taxonomia e comprovação do seu potencial biotecnológico para aplicação na cultura da palma, sob a forma de inoculantes biológicos e biofertilizantes.

Quarenta e dois isolados endofíticos apresentaram capacidade de solubilização de fosfato. O isolado JNFb P15 apresentou índice de alta solubilização de fosfato inorgânico, sendo considerado como um bom solubilizador de P. As bactérias diazotróficas endofíticas presentes nas regiões do Agreste e do Sertão de Pernambuco apresentaram índice de diversidade aproximado. A análise da Equitabilidade entre as bactérias estudadas foi semelhante para as regiões estudadas. 


\section{Referências}

BASHAN, Y.; HOLGUIN, G.; DE-BASHAN, L. E. Azospirillumplant relationships: physiological, molecular, agricultural, and environmental advances (1997-2003). Canadian Journal of Microbiology, Ottawa, v. 50, n. 8, p. 521-577, 2004. PMid:15467782. http://dx.doi.org/10.1139/w04-035

BERRAQUERO, F. R.; BAYA, A. M.; CORMENZANA, A. R. Establecimiento de índices para el estudio de la solubilización de fosfatos por bacterias del suelo. Ars Pharmaceutica, Granada, v. 17, n. 4, p. 399-406, 1976.

CARDOSO, I. C. M. et al. Ocorrência de bactérias endofíticas do gênero Azospirillum em arroz irrigado no estado de Santa Catarina. Revista de Ciências Agroveterinárias, Lages, v. 9, n. 2, p. 178-186, 2010.

CHAGAS JUNIOR, A. F. et al. Capacidade de solubilização de fosfatos e eficiência simbiótica de rizóbios isolados de solos da Amazônia. Acta Scientiarum: Agronomy, Maringá, v. 32, n. 2, p. 359-366, 2010.

COMPANT, S.; CLÉMENT, C.; SESSITSCH, A. Plant growth promoting bacteria in the rhizo- and endosphere of plans: their role, colonization, mechanisms involved and prospects for utilization. Soil Biology and Biochemistry, Oxford, v. 42, n. 5, p. 669-678, 2010. http://dx.doi.org/10.1016/j.soilbio.2009.11.024

DÖBEREINER, J.; BALDANI, V. L. D.; BALDANI, J. I. Como isolar e identificar bactérias diazotróficas de plantas não-leguminosas. Brasília: EMBRAPA-SPI; Itaguaí: EMBRAPA-CNPAB, 1995.60 p.

GYANESHWAR, P. et al. Role of soil microorganisms in improving $\mathrm{P}$ nutrition of plants. Plant and Soil, The Hague, v. 245, n. 1, p. 83-93, 2002. http://dx.doi.org/10.1023/A:1020663916259

INUI-KISHI, R. N. et al. Phosphorus solubilizing and iaa production activities in plant growth promoting rhizobacteria from brazilian soils under sugarcane cultivation. ARPN Journal of Engineering and Applied Sciences, Pakistan, v. 7, n. 11, p. 1446-1454, 2012.

KIRCHHOF, G. et al. Molecular microbial ecology approaches applied to diazotrophs associated with non-legumes. Soil Biology and Biochemistry, Oxford, v. 29, n. 5-6, p. 853-862, 1997. http:// dx.doi.org/10.1016/S0038-0717(96)00233-7

MASSENSSINI, A. M. Solubilização de fosfatos mediada por microrganismos do solo de plantio de eucalipto. 2007. $95 \mathrm{f}$. Dissertação (Mestrado)-Universidade Federal de Viçosa, Viçosa, 2007.

NAUTIYAL, C. S. An efficient microbiological growth medium for screening phosphate solubilizing microorganisms. FEMS Microbiology Letters, Amsterdam, v. 170, n. 1, p. 265-270, 1999. http://dx.doi.org/10.1111/j.1574-6968.1999.tb13383.x

NÓBREGA, R. S. A. et al. Caracterização fenotípica e diversidade de bactérias diazotróficas associativas isoladas de solos em reabilitação após a mineração de bauxita. Revista Brasileira de Ciência do Solo, Viçosa, v. 28, n. 2, p. 269-279, 2004.

OLIVEIRA, A. L. M. et al. Colonization of sugarcane plantlets by mixed inoculations with diazotrophic bacteria. European Journal of Soil Biology, Paris, v. 45, n. 1, p. 106-113, 2009. http://dx.doi. org/10.1016/j.ejsobi.2008.09.004

PEDRINHO, E. A. N. Isolamento e caracterização de bactérias promotoras de crescimento em milho (Zea mays). 2009. $74 \mathrm{f}$. Tese (Doutorado)-Faculdade de Ciências Agrárias e Veterinárias, Universidade Estadual Paulista, Jaboticabal, 2009.

PIELOU, E. C. The use of point to plant distances in the study of the pattern of plant populations. Journal of Ecology, London, v. 47, n. 3, p. 607-613, 1959. http://dx.doi.org/10.2307/2257293
RODRIGUES NETO, J.; MALAVOLTA JÚNIOR, V. A.; VICTOR, O. Meio simples para o isolamento e cultivo de Xanthomonas campestris pv. Citri tipo B. Summa Phytopathologica, Piracicaba, v. 12, n. 1-2, p. 16, 1986.

SALA, V. M. R. et al. Ocorrência e efeito de bactérias diazotróficas em genótipos de trigo. Revista Brasileira de Ciência do Solo, Viçosa, v. 29, n. 3, p. 345-352, 2005.

SANTOS, C. E. R. S. Diversidade de rizóbio nativo da região Nordeste do Brasil capaz de nodular amendoim (Arachis hypogaea), Stylosanthes e Aeschynomene. 2001. 178 f. Tese (Doutorado)-Universidade Federal Rural do Rio de Janeiro, Seropédica, 2001.

SANTOS, D. C. et al. Manejo e utilização da palma forrageira (Opuntia e Nopalea) em Pernambuco. Recife: IPA, 2006. 48 p. (IPA Documentos, 30).

SANTOS, I. B. et al. Bactérias diazotróficas associadas a raízes de cana-de-açúcar: solubilização de fósforo inorgânico e tolerância à salinidade. Bioscience Journal, Uberlândia, v. 28, p. 142-149, 2012. Suplemento 1.

SHANNON, C. E.; WEAVER, W. The mathematical theory of communication. Urbana: University Ilinois Press, 1949.

SILVA FILHO, G. N.; NARLOCH, C.; SCHARF, R. Solubilização de fosfatos naturais por microrganismos isolados de cultivos de Pinus e Eucalyptus de Santa Catarina. Pesquisa Agropecuária Brasileira, Brasília, v. 37, n. 6, p. 847-854, 2002. http://dx.doi. org/10.1590/S0100-204X2002000600014

SILVA FILHO, G. N.; VIDOR, C. Solubilização de fosfato por microrganismos na presença de fontes de carbono. Revista Brasileira de Ciência do Solo, Viçosa, v. 24, n. 6, p. 311-319, 2000

SILVA, A. C. S. et al. Ocorrência de bactérias solubilizadoras de fosfato nas raízes de plantas de importância econômica em Manaus e Rio Preto da Eva, Amazonas. Journal of Biotechnology and Biodiversity, Tocantins, v. 2, n. 1, p. 37-42, 2011.

SOBRAL, J. K. A comunidade bacteriana endofítica e epifítica de soja (Glycine max) e estudo da interação endófitos-planta. 2003. $174 \mathrm{f}$. Tese (Doutorado)-Escola Superior de Agricultura "Luiz de Queiroz", Piracicaba, 2003.

SOUCHIE, E. L. et al. Solubilização de fosfatos em meios sólido e líquido por bactérias e fungos do solo. Pesquisa Agropecuária Brasileira, Brasília, v. 40, n. 11, p. 1149-1152, 2005. http://dx.doi. org/10.1590/S0100-204X2005001100015

TAN, Z.; HUREK, T.; REINHOLD-HUREK, B. Effect of $\mathrm{N}$-fertilization, plant genotype and environmental conditions on nifH gene pools in roots of rice. Environmental Microbiology, Oxford, v. 5, n. 10, p. 1009-1015, 2003. http://dx.doi.org/10.1046/ j.1462-2920.2003.00491.x

VERMA, S. C.; LADHA, J. K.; TRIPATHI, A. K. Evaluation of plant growth promoting and colonization ability of endophytic diazotrophs from deep water rice. Journal of Biotechnology, Varanasi, v. 91, n. 2-3, p. 127-141, 2001. http://dx.doi.org/10.1016/ S0168-1656(01)00333-9

WHITELAW, M. A. Growth promotion of plant inoculated with phosphate-solubilizing fungi. Advances in Agronomy, New York, v. 69, p. 99-151, 2000. http://dx.doi.org/10.1016/S00652113(08)60948-7

Recebido: 19 mar. 2013 Aprovado: 17 jun. 2014 